Revista Brasileira de História \& Ciências Sociais - RBHCS

Vol. 13 No 26, Janeiro - Junho de 2021

\title{
Operação Acolhida: Entre a Militarização e a Assistência Social
}

\section{“Operação Acolhida": Between Militarization and Social Assistance}

\author{
Ariane Rego de Paiva* \\ Ana Gabriela de Paiva Gonçalves **
}

Resumo: O artigo se refere a resposta do governo brasileiro à imigração venezuelana através da Operação Acolhida. Foram utilizadas análises bibliográficas, instrumentos jurídicos-normativos internacionais e nacionais, além de entrevistas realizadas em 2018 com os representantes do poder público das três esferas de governo e de entidades da sociedade civil envolvidos nas ações em Boa Vista e Pacaraima no estado de Roraima. Os principais resultados apontam para o protagonismo das Forças Armadas na ação humanitária, com rebatimentos significativos na relação Estado e sociedade civil para a construção de uma política de proteção aos refugiados, com baixo controle social dos gastos públicos e dos processos decisórios, e subordinação da política pública de assistência social.

Palavras-chave: Refúgio. Acolhimento. Assistência Social. Militarização.

Venezuelanos.

Abstract: The article refers to the answer of Brazilian government to Venezuelan immigration through the Operação Acolhida. Bibliographical analysis of the international and national legal-normative instruments were used, besides interviews conducted in 2018 with representatives of public authorities of the three government spheres and entities of the civil society

\footnotetext{
* Doutora pelo Programa de Estudos Pós-Graduados em Política Social pela Universidade Federal Fluminense - UFF/Niterói. Atualmente é Professora Assistente do Departamento de Serviço Social da PUC - Rio, onde desenvolve projetos na Linha de Pesquisa: Violência, Direitos, Serviço Social e Políticas Intersetoriais. É líder do Grupo de Pesquisa do CNPq Estado, Sociedade, Políticas e Direitos Sociais - GESPD/PUC-Rio; Vice-líder do Grupo de Pesquisa do CNPq Rede Interinstitucional de Cátedras Sérgio Vieira de Mello - PUC-Rio; pesquisadora do Grupo de Pesquisa do CNPq Núcleo de Avaliação e Análise de Políticas Sociais - UFF; e faz parte da Comissão Gestora da Cátedra Sérgio Vieira de Mello do ACNUR na PUC-Rio.

** Mestra pelo Programa de Pós-Graduação em Serviço Social da Pontifícia Universidade Católica do Rio de Janeiro.
} 


\section{Revista Brasileira de História \& Ciências Sociais - RBHCS}

Vol. 13 No 26, Janeiro - Junho de 2021

involved in the actions on Boa Vista and Pacaraima, in the state of Roraima. The main results points to the protagonism of the armed forces in the humanitarian act, with significant impact on the relationship between State and civil society to build a new refugee protection policy, with low social control of public expenses and decision processes, and subordination of the social assistance's public policy.

Keywords: Refuge. Reception. Social Assistance. Militarization; Venezuelans.

\section{Breve Introdução ao Significado Político do Refúgio}

Este trabalho expressa a sistematização e análise dos dados coletados no interior de uma pesquisa mais ampla iniciada em 2016 e ainda em andamento, realizada pelo Grupo de Pesquisa Estado, Sociedade, Políticas e Direitos Sociais da Pontifícia Universidade Católica do Rio de Janeiro (PUC Rio), que possui financiamento da universidade e do Fundo Carlos Chagas Filho de Amparo à Pesquisa do Estado do Rio de Janeiro (FAPERJ). Para este $\operatorname{artigo}^{1}$, que se refere especificamente à uma análise sobre a situação dos refugiados venezuelanos no Brasil e a resposta do governo brasileiro para acolhimento e integração desta população através da Operação Acolhida, foi utilizado levantamento bibliográfico, análise dos instrumentos jurídicosnormativos do Alto Comissariado das Nações Unidas para os Refugiados (ACNUR), a legislação brasileira, análise dos documentos produzidos pelo governo federal para regulação da operação interministerial, entrevistas realizadas com os representantes do poder público e de entidades da sociedade civil envolvidos na Operação Acolhida nas cidades de Boa Vista e Pacaraima no estado de Roraima em 2018, observações realizadas durante visitas técnicas operadas por pesquisadores da PUC-Rio através de atividades da Cátedra

\footnotetext{
1 Este trabalho foi apresentado previamente em Mesa Coordenada no $8^{0}$ Encontro Internacional de Política Social, que ocorreu em novembro de 2020, e depois revisado para esta publicação.
} 


\section{Revista Brasileira de História \& Ciências Sociais - RBHCS}

Vol. 13 No 26, Janeiro - Junho de 2021

Sérgio Vieira de Mello² em 2018 e 2019, além de notícias em jornais de grande circulação do período entre 2018 e 2019 sobre o tema.

Os fluxos de migrações internacionais contemporâneos envolvem múltiplos determinantes do desenvolvimento capitalista, das questões climáticas, das relações e disputas geopolíticas e diplomáticas entre os Estados. As normativas dos organismos internacionais e as legislações dos Estados nacionais sobre o tema da migração e refúgio baseados no princípio de soberania - ou nos dizeres de Di Cesare (2020), balizadas pelo modelo hegemônico estadocêntrico de divisão do mundo, legitimam a regularidade da mobilidade, vão construindo diferentes categorias para o "status" migratório, com políticas migratórias e de cidadania que podem ou não facilitar o acolhimento e a assistência dos sujeitos em trânsito em uma perspectiva mais ampla dos direitos humanos (migrantes econômicos, refugiados, migrantes humanitários, apátridas, deslocados ambientais, etc).

No âmbito do direito internacional foram definidas diferenças entre migrantes e refugiados. A migração vem sendo compreendida como um processo voluntário, onde o deslocamento ocorre, muitas vezes, devido a busca por melhores condições de vida e tendo um caráter econômico. A diferenciação com o refúgio está nas categorizações das "violações dos direitos humanos" e no "fundado temor de perseguição". Na definição clássica, os refugiados são considerados:

[...] Como toda pessoa que, como resultado de acontecimentos ocorridos antes de $1^{\circ}$ de janeiro de 1951 e devido a fundados temores de ser perseguido por motivos de raça, religião, nacionalidade, por pertencer a determinado grupo social e por suas opiniões políticas, se encontre fora do país de sua nacionalidade e não possa ou, por causa dos ditos temores, não queira recorrer à proteção de tal país; ou que, carecendo de nacionalidade e estando, em consequência de tais acontecimentos, fora do país onde tivera sua residência habitual, não possa ou por temor fundado não queira regressar a ele (BARRETO, 2010, p.15).

\footnotetext{
2 As Cátedras são implementadas desde 2003 pelo ACNUR em parcerias com centros universitários nacionais e o Comitê Nacional para Refugiados (CONARE), com intuito de garantir estudos, pesquisas e acesso a serviços e direitos aos solicitantes de refúgio e refugiados no Brasil.
} 
Esta definição passou por revisões ao longo dos anos, para atender às novas exigências das situações de refúgio contemporâneas, considerando novos territórios em conflitos. Para a América Latina, o principal marco normativo internacional passou a ser a Declaração de Cartagena de 1984, que além da definição clássica, redefiniu o conceito referente à grave e generalizada violação de direitos humanos para garantir o direito ao refúgio. Esta Declaração incluiu pessoas que fugiram de seu país de origem ou residência habitual porque sua vida, segurança ou liberdade foram (ou poderiam ser) ameaçadas pela violência generalizada, pela agressão estrangeira, por conflitos internos, pela violação massiva de direitos humanos ou outras circunstâncias que tenham perturbado gravemente a ordem pública.

Esta ampliação tem impactos ao regime de refúgio e levanta muitas problemáticas, porém este tema não será possível de ser abordado neste pequeno texto. Cabe, porém, ressaltar que a Lei brasileira que se destina à proteção dos refugiados, Lei 9.474/1997, adotou em sua definição a "grave e generalizada violação de direitos humanos" para fins de reconhecimento do status de refugiado.

Segundo o relatório "Tendências Globais" do ACNUR (2020), em 2019 o deslocamento forçado afetou $1 \%$ da humanidade, ou seja, 1 em cada 97 pessoas. Até dezembro de 2019 foram 79,5 milhões de pessoas deslocadas de forma forçada e destes, 29,6 milhões eram considerados refugiados, por estarem fugindo de conflitos, guerras e perseguições; 4,2 milhões eram solicitantes de refúgio; e 45,7 milhões eram considerados deslocados internos, ou seja, que não cruzaram a fronteira de seus países. $\mathrm{O}$ aumento significativo de deslocamentos entre 2018 (eram 70,8 milhões de deslocados) e 2019 se deu principalmente pelos conflitos da República Democrática do Congo, Iêmen e Síria, e pelo deslocamento dos venezuelanos fora de seu país.

Desde 2015 o Brasil tem sido um dos destinos da migração venezuelana, principalmente pela fronteira terrestre no estado de Roraima, em decorrência da crise política, econômica e social pela qual atravessa a 


\section{Revista Brasileira de História \& Ciências Sociais - RBHCS}

Vol. 13 No 26, Janeiro - Junho de 2021

Venezuela. Em fins de 2016, a entrada pela fronteira foi intensificada, gerando conflitos entre os atores políticos governamentais da esfera federal, estadual e municipal que atuam na região, além de reações da sociedade civil.

A chegada desses contingentes vem produzindo tensões no sistema de migração e refúgio brasileiro, particularmente na organização e gestão da fronteira e no aparato normativo-institucional, o que inclui a proteção social através de equipamentos para acolhimento e assistência aos sujeitos e famílias deslocadas, o que também inclui a política de integração. Estima-se que o fluxo global de deslocados venezuelanos até 2019 tenha sido da ordem de 3,6 milhões de pessoas (ACNUR, 2020). De acordo com o ACNUR (2020) até o final de 2019 eram 1.771.237 refugiados venezuelanos na Colômbia, 452.712 no Chile, 377.864 no Peru, 374.045 no Equador e 123.507 no Brasil.

Desde o início da intensificação do deslocamento de venezuelanos ao Brasil, sua condição migratória foi matéria de debates, disputas e conflitos sobre a ajuda humanitária e se era uma questão de refúgio ou de migração econômica. Em matéria do jornal alemão Deutsche Welle (DW), de 22/02/2019, a demora de resposta e as negativas do órgão brasileiro responsável pelas avaliações das solicitações de refúgio, o Comitê Nacional para os Refugiados (CONARE), foi assim explicada:

\footnotetext{
"Para ter o pedido aceito como refugiado é preciso que a pessoa preencha alguns pré-requisitos, como estar no Brasil por motivo de perseguição no país de origem por questões de raça, religião e opiniões políticas, além de outros detalhes. No caso da Venezuela, os pedidos que chegam são basicamente pela questão econômica daquele país, por isso muitos pedidos são negados", diz Bernardo Lafertè, coordenador-geral do Conare (DW, 2019).
}

$\mathrm{Na}$ mesma reportagem, houve menção à necessidade de ajuda humanitária aos venezuelanos pelo representante do CONARE, sem que se considerasse a possibilidade do refúgio. Também apareceu outras alternativas como o visto para trabalho, estudo ou reunião familiar previstos em outra legislação (Lei de Migração, Lei n. 13.445/2017). 
Revista Brasileira de História \& Ciências Sociais - RBHCS

Vol. 13 No 26, Janeiro - Junho de 2021

Com a justificativa de agilizar a situação migratória dos venezuelanos e com o não reconhecimento pelo Estado brasileiro da situação da Venezuela como uma grave e generalizada violação de direitos humanos, o governo brasileiro publicou a Portaria Interministerial $\mathrm{n}^{0}$ 9, em 14 de março de 2018, que dava direito à residência temporária aos deslocados daquele país. No mesmo mês em que o ACNUR lançou uma nota de orientação, incentivando os países que adotaram a definição ampliada de refugiados da Declaração de Cartagena, considerarem-na no caso dos venezuelanos.

A burocratização com documentos impossibilitou muitos migrantes a solicitarem esta autorização, buscando a solicitação de refúgio como solução de regularização de imigração - que não requer documentos -, o que obrigou o governo brasileiro a flexibilizar o registro dos venezuelanos para autorização de residência em uma nova Portaria Interministerial, de $\mathrm{n}^{0}$ 15, de 27 de agosto de 2018. A resistência do governo brasileiro em deferir o regime de refúgio aos venezuelanos pode ser analisada no trecho do texto do Ministério da Justiça (2018) ao apresentar as mudanças na portaria:

Agora, por meio da publicação hoje anunciada, procurouse adequar as exigências à realidade vivenciada no fluxo migratório venezuelano, permitindo que até mesmo aqueles que não tenham todos os documentos pessoais possam, se desejarem, solicitar a residência temporária.

Pretende-se, assim, acertar a condição jurídica dos nacionais da Venezuela, viabilizando, àqueles que não desejam o reconhecimento da condição de refugiado, por serem imigrantes econômicos que constantemente regressam ao seu país de origem para apoiar familiares que lá permaneceram, o deferimento de autorização de residir no Brasil (MINISTÉRIO DA JUSTIÇA 2018 grifos nossos).

No trecho destacado, a categoria de imigrantes econômicos foi evocada para distinguir os venezuelanos, o que os fragiliza nos termos de proteção migratória, pois eram vistos como deslocados espontâneos e que poderiam regressar ao seu país de origem quando quisessem. Por este trecho, identifica-se a dificuldade em se estabelecer o significado de "grave e 
Revista Brasileira de História \& Ciências Sociais - RBHCS

Vol. 13 No 26, Janeiro - Junho de 2021

generalizada violação de direitos humanos" para fins de refúgio e o superdimensionamento do "fundado temor de perseguição" nas avaliações de reconhecimento das solicitações. Para proteção à população refugiada, os direitos civis e políticos se sobrepõem aos direitos econômicos e sociais. A ausência de definições mais objetivas abre a possibilidade do poder discricionário do Estado em tomar decisões sobre a situação dos migrantes, o que implica em decisões muito mais de cunho político do que normativo-legal (CORRÊA et al, 2015).

Em dezembro de 2019, já sob a responsabilidade do governo de Jair Bolsonaro, o CONARE aprovou em bloco 21.432 solicitações de venezuelanos como refugiados, declarando a situação de acordo com o que consta no ordenamento jurídico brasileiro, baseado na "grave e generalizada violação de diretos humanos" para fins de refúgio. Muitos venezuelanos obtiveram residência temporária no Brasil - cerca de 20 mil registros até 2019, conforme informações do Ministério da Justiça (2019).

\section{A Assistência Social brasileira e sua intersecção com o Sistema de Refúgio}

As políticas migratórias exigem efetiva acolhida e inserção na comunidade nacional (IMDH, 2014). No Brasil, o período de redemocratização foi um importante marco para novas formas de organização e regulamentação das políticas públicas e sociais, dentre elas a política para migrantes e refugiados. Na década de 1990, o governo de Fernando Henrique Cardoso (1996 - 2002) deu início ao processo de institucionalidade à política de migração atrelada aos Direitos Humanos, com a elaboração do Primeiro Programa Nacional de Direitos Humanos - PNDH I, de 1996, e a aprovação da já citada Lei do Refúgio, de 1997. Esta Lei instituiu o CONARE, que possui representação do ACNUR, órgãos do governo federal, e representantes da sociedade civil para tratar especialmente das requisições sobre a condição de refúgio no país. 
Revista Brasileira de História \& Ciências Sociais - RBHCS

Vol. 13 No 26, Janeiro - Junho de 2021

Para a "integração"3 dos refugiados e migrantes no país de acolhimento há expectativas de sua inserção em processos que abrangem aspectos socioeconômicos e culturais, inserção no trabalho, moradia, o aprendizado da língua, a utilização de serviços públicos, e a construção de relações sociais com membros da comunidade local (AGER e STRANG, 2008 apud MOREIRA, 2010). Houve, porém, pouco investimento além dos aspectos jurídicos normativos para elaboração e implementação de uma política específica que levasse em consideração as particularidades das necessidades destes sujeitos no Brasil, principalmente quando apresentam situações de vulnerabilidades socioeconômicas.

Mesmo com todas as legislações que dão sustentação ao processo de acolhimento e proteção social aos imigrantes em situações regularizadas pelo Estado, incluindo os solicitantes de refúgio e os refugiados, não se estabeleceu uma aproximação entre o governo federal e os outros entes de forma continuada e satisfatória para sensibilizar os órgãos públicos para a situação desta população que é muito heterogênea e requer atenções específicas para suas demandas. Identifica-se uma ausência clara de políticas equitativas para "integração local” deste público. Além disso, a população migrante e refugiada não tem sido incluída nos espaços decisórios para a formulação de ações para atender suas demandas. São as organizações não governamentais que historicamente vêm destinando atendimentos para estes segmentos. Este cenário tem sofrido algum tipo de alteração com o aumento do fluxo migratório no país e que tem tensionado as respostas do Estado brasileiro e seus governantes.

Uma das políticas das quais os migrantes, dentre eles os solicitantes de refúgio e refugiados, podem acessar é a assistência social, que junto com a saúde e a previdência social, compõem o sistema de seguridade social brasileiro. Esta política aparece como um direito na Constituição Federal de 1988 e foi regulamentada pela Lei Orgânica da Assistência Social (LOAS),

3 Integração local é o termo oficial utilizado pela agência internacional para se referir a uma das soluções duráveis para refugiados. Trata-se dos complexos processos de inserção dos refugiados na comunidade de acolhida - temos críticas ao termo, porém não há como desenvolvê-las suficientemente neste trabalho. 
Revista Brasileira de História \& Ciências Sociais - RBHCS

Vol. 13 No 26, Janeiro - Junho de 2021

Lei $\mathrm{n}^{\circ}$ 8.742, de 7 de dezembro de 1993, que em seu artigo 4, apresenta seus princípios norteadores:

I - supremacia do atendimento às necessidades sociais sobre as exigências de rentabilidade econômica;

II - universalização dos direitos sociais, a fim de tornar o destinatário da ação assistencial alcançável pelas demais políticas públicas;

III - respeito à dignidade do cidadão, à sua autonomia e ao seu direito a benefícios e serviços de qualidade, bem como à convivência familiar e comunitária, vedando-se qualquer comprovação vexatória de necessidade;

IV - igualdade de direitos no acesso ao atendimento, sem discriminação de qualquer natureza, garantindo-se equivalência às populações urbanas e rurais;

V - divulgação ampla dos benefícios, serviços, programas e projetos assistenciais, bem como dos recursos oferecidos pelo Poder Público e dos critérios para sua concessão (Grifos nossos) (BRASIL, 1993).

A Lei não faz distinção entre cidadãos brasileiros e imigrantes, reforçando o artigo constitucional 203 que aborda a assistência social enquanto política pública destinada a quem dela necessitar. Desde 2005, a política de assistência social tem sido implementada em todo o território brasileiro a partir de um novo sistema de gestão pública, denominado Sistema Único de Assistência Social (SUAS). Na perspectiva de ofertar serviços e benefícios, a proteção social da assistência social foi dividida em níveis hierarquizados: proteção social básica, proteção social especial de média e alta complexidade. Os migrantes têm os mesmos direitos de acessarem os benefícios e serviços socioassistenciais, desde que cumpram os critérios de elegibilidade. Muitos têm sido incluídos no Programa Bolsa Família (PBF) e em outras ações propostas pelos governos federal, estadual e municipal.

No caso especificamente do acolhimento institucional, a situação dos migrantes aparece na normativa que se destina a delimitar os serviços desta política pública. De acordo com a Tipificação Nacional dos Serviços Socioassistenciais, o acolhimento provisório:

É previsto para pessoas em situação de rua e desabrigo por 
abandono, migração e ausência de residência ou pessoas em trânsito e sem condições de auto-sustento. Deve estar distribuído no espaço urbano de forma democrática, respeitando o direito de permanência e usufruto da cidade com segurança, igualdade de condições e acesso aos serviços públicos. O atendimento a indivíduos refugiados ou em situação de tráfico de pessoas (sem ameaça de morte) poderá ser desenvolvido em local específico, a depender da incidência da demanda (CNAS, 2009, p.31 - grifos nossos).

Apesar dos migrantes se constituírem como público-alvo de qualquer serviço da assistência social, seja pela situação de pobreza ou de violência e violações de direitos a que estejam expostos, a condição particular de chegada ao Brasil quando não possuem referências de moradia e não possuem recursos financeiros para aluguel, os torna público para o acolhimento nos abrigos, podendo haver serviços específicos, dependendo da incidência da demanda. No entanto, a Tipificação não avança para o levantamento de ações específicas destinadas para estes segmentos e suas diversidades - como é o caso das crianças e adolescentes separadas ou desacompanhadas de familiares/responsáveis, incluindo-os nas mesmas requisições ao atendimento da população em situação de rua.

No caso do acolhimento de venezuelanos em Roraima, o status migratório não foi o critério de seleção para inserção nos abrigos e também suas questões particulares não foram consideradas para as primeiras ações de abrigamento. O que levou a intervenção do Estado para abertura dos abrigos foi exatamente a situação de rua de um contingente grande de pessoas, e a prática higienista e segregadora para controle daquela população.

\section{Operação Acolhida: alguns apontamentos nas relações institucionais}

A chegada dos venezuelanos nas cidades de Pacaraima e Boa Vista, desde meados de 2015, trouxe impactos para os frágeis sistemas de serviços públicos, em especial os de saúde, educação e assistência social, instalados no estado de Roraima. A necessidade de permanecerem perto da Venezuela para levar dinheiro, alimentos e remédios para familiares, além da dificuldade de 


\section{Revista Brasileira de História \& Ciências Sociais - RBHCS}

Vol. 13 No 26, Janeiro - Junho de 2021

saída do território de Roraima para outras regiões do país, fizeram com que houvesse uma concentração de pessoas em áreas públicas, sem moradia, ocupando praças e prédios públicos e privados abandonados. Compreender a complexidade da situação da migração nesta fronteira requer não só reconhecer as questões políticas e econômicas da Venezuela, como também buscar entendimento nas desigualdades brasileiras e na precariedade dos serviços públicos implantados daquela região.

Uma das queixas dos representantes do governo estadual e municipal era a ausência de estrutura para atender o novo contingente de pessoas e a necessidade de maiores recursos financeiros para assumirem ampliação de serviços básicos. De acordo com entrevistas realizadas em 2018, tanto o governo estadual quanto o municipal de Boa Vista haviam tentado apoio federal para lidar com a intensificação da chegada dos migrantes, a princípio os indígenas, depois um contingente cada vez maior de venezuelanos de várias partes do país, mas não obtiveram êxito.

Em 2018 ocorria o processo de pleito eleitoral para presidência da República, bem como para governadores e para a troca do legislativo federal e estadual. A situação da migração venezuelana foi tema de repercussão nacional, e virou uma das principais pautas de disputa, principalmente entre os candidatos do estado de Roraima, e mobilizou reações dos políticos e de instituições locais de várias naturezas, entre elas, o discurso de xenofobia, de nacionalismo e a consequente ação de violência contra venezuelanos. $\mathrm{O}$ aumento dos deslocamentos foi tensionando as relações sociais estabelecidas, e os migrantes eram continuamente acusados de causarem epidemias, de serem responsáveis pelo aumento de criminalidade e violência na região.

As primeiras ações dos governos locais foram criar abrigos improvisados para retirar as pessoas da situação de rua, além de tentativas de fechamento da fronteira, e a proposta de criação de uma barreira sanitária para impedir a mobilidade dos venezuelanos. Muitas organizações não governamentais, nacionais e internacionais, chegaram ao município e se estabeleceram para atendimento aos venezuelanos, o que contribuiu para mudanças no cenário político e econômico local. 
Revista Brasileira de História \& Ciências Sociais - RBHCS

Vol. 13 No 26, Janeiro - Junho de 2021

Em abril de 2018, na tentativa de fechar a fronteira com a Venezuela e impedir o fluxo migratório para o estado, o governo estadual de Roraima ajuizou a Ação Civil Originária 3121 no Supremo Tribunal Federal contra a União4. Em agosto de 2018, a governadora do estado publicou o Decreto 25.681-E, que propunha um "choque de ordem”, com inúmeras medidas que impediam os imigrantes a acessarem serviços básicos e os criminalizava, chamando as forças policiais à garantirem sua deportação ou expulsão se necessário (PODER JUDICIÁRIO DO ESTADO DE RORAIMA, 2018). Todo este processo entre o acolhimento e a hostilidade com os imigrantes foi criando o que Fassin (2015) chama de economia política da imigração, pois envolve os interesses políticos e econômicos que decidem por receber ou não os imigrantes, e que vem acompanhada, ou melhor, relacionada a uma economia moral do refúgio, ou seja, a produção, circulação e apropriação de normas, e obrigações, valores e afetos sobre o tema dos refugiados.

A criação da Operação Acolhida, iniciada em fevereiro de 2018, foi um instrumento de ação tomado pelo governo Temer (2016-2018), como resposta ao fluxo de venezuelanos que ingressou no país, para atender às pressões dos governos estadual de Roraima e municipal de Boa Vista, além da repercussão midiática nacional e internacional. A referida operação centralizada na esfera federal é designada como "força tarefa logística humanitária em Roraima”, e envolve vários órgãos federais (Ministério da Defesa, Polícia Federal, ANVISA, Ministério da Cidadania, Ministério de Direitos Humanos, Defensoria Pública da União), além de diversas agências internacionais (ACNUR, OIM, UNFPA, UNICEF) na sua organização e participação de entidades da sociedade civil (nacionais e internacionais) e dos demais entes federativos.

Conforme aponta Gomarasca (2017) a política humanitária, no caso das migrações, relaciona-se intimamente à reação securitária e dos controles de fronteiras. Pode-se afirmar que uma política conforma a outra. Concomitante ao processo de construção dos abrigos nas cidades de Pacaraima e Boa Vista,

4 Esse pedido foi indeferido pela Ministra Rosa Weber. Acesso em: http://www.stf.jus.br/portal/cms/verNoticiaDetalhe.asp?idConteudo $=386012$ 


\section{Revista Brasileira de História \& Ciências Sociais - RBHCS}

Vol. 13 No 26, Janeiro - Junho de 2021

em Roraima, e do processo chamado de "interiorização" - que se conforma a partir da transferência de venezuelanos para outros estados brasileiros, o outro "braço" da Operação é o monitoramento da fronteira e o encaminhamento dos sujeitos para a regularização de sua condição migratória (pedido de residência ou solicitação de refúgio).

Apesar de todos os atores envolvidos na Operação, o grande protagonista na fronteira e nos abrigos é o Ministério da Defesa, com atuação das Forças Armadas, que organiza a logística e a segurança das ações. Os chamados “abrigos humanitários”, estão sob o controle e gestão do Ministério da Defesa, da Secretaria Estadual de Trabalho e Bem-Estar Social de Roraima, e do ACNUR. Cada abrigo possui parcerias com organizações não governamentais internacionais e nacionais, que se responsabilizam pelas atividades administrativas e cotidianas como o trabalho com as crianças, atividades com as mulheres, etc. Na época das entrevistas, em 2018, eram 11 abrigos e atualmente são 13, onde estão abrigados separadamente imigrantes venezuelanos não indígenas e indígenas das etnias Warao e Eñap’á.

Os abrigos são estruturados com barracas do Exército ou da ONU ou com casas montáveis utilizadas em campos de refugiados em outros locais do mundo (completamente desadaptadas ao calor do estado de Roraima). A organização lembra as imagens de campos de refugiados, tanto pela quantidade de pessoas quanto pela disponibilidade das células de moradia, porém, os abrigos murados e com controle de entrada e saída pelo Exército ocupam o espaço urbano e as pessoas podem circular pela cidade. Apesar da parceria com o Ministério da Cidadania e da legislação brasileira sobre o SUAS, não é a lógica da assistência social que rege os abrigos. Há um híbrido entre a proteção humanitária internacional e a percepção de que os abrigos atendem uma população que se encontrava em situação de rua - são chamados de "usuários" pelos profissionais que atendem nos abrigos e possuem regras que lembram as instituições assistenciais destinadas à população de rua, podendo inclusive serem “advertidos" e "desligados" no caso de descumprimento dessas regras (envolvimento em brigas, furtos, etc). 
Revista Brasileira de História \& Ciências Sociais - RBHCS

Vol. 13 No 26, Janeiro - Junho de 2021

As coordenações técnicas dos abrigos são ocupadas por profissionais relacionados às áreas do direito e das relações internacionais, não havendo equipes técnicas previstas pelo SUAS. Identificamos somente assistentes sociais, psicólogos e antropólogos nos dois abrigos onde a Secretaria Estadual de Bem-Estar ocupa a gestão, que são os abrigos destinados aos indígenas estes abrigos possuem uma perspectiva de continuidade, pois os indígenas não estavam inseridos no programa de interiorização. Nos demais abrigos fica nítida a ausência de profissionais da área social, e consequentemente nas mediações de conflitos, nas poucas atividades socioeducativas e pedagógicas (às vezes nenhuma), o que nos leva a pensar no caráter provisório e precário com que se atende os migrantes, com preocupações muito mais regulativas no campo jurídico-normativo da sua condição migratória, do que com suas questões sociais, econômicas e psicológicas. Na realidade de Roraima, os abrigos são provisórios, pois a "meta" é a "interiorização" para a "integração", sem considerar que a situação requer ações duradouras e sustentáveis (LEÃO, 2018).

A chegada das forças armadas foi vista como positiva pelos outros parceiros que atendem às necessidades dos migrantes em Boa Vista, apesar de apontarem as contradições deste processo. Ouvimos profissionais das organizações da sociedade civil, da Universidade Federal, da Polícia Federal, das Forças Armadas e dos poderes estadual e municipal. A estrutura de abrigos e alimentação melhoraram, pois houve destinação de recursos federais para isso e agilidade para mudar a infraestrutura, enquanto que anteriormente, havia alagamentos, não tinha sanitários suficientes, toda a alimentação era arrecadada por voluntários e com pouca distribuição pela prefeitura e órgão estadual, aquém da necessidade em quantidade e de valores nutricionais.

Para os representantes dos poderes públicos da esfera estadual e municipal, os recursos deveriam ter sido distribuídos aos entes, respeitando o pacto federativo de descentralização, para fortalecimento dos serviços existentes nos municípios e atendimento também da população de Roraima. Este foi um ponto chave na disputa entre os três entes federativos. Uma das principais críticas dos entrevistados das entidades da sociedade civil foi em 


\section{Revista Brasileira de História \& Ciências Sociais - RBHCS}

Vol. 13 No 26, Janeiro - Junho de 2021

relação à grande monta de recursos federais para a Operação, sem fiscalização dos gastos, sem controle e participação social. O general, responsável pela Operação, fazia um encontro quinzenal com todas as entidades, para prestação de contas e atualização da situação, porém existiam queixas de que de fato, não era um espaço horizontalizado. Eram encontros informativos e de direção dada pelo Ministério da Defesa.

Os militares também trouxeram o sentimento de proteção $\mathrm{e}$ segurança ao local. Os entrevistados relataram dias tensos, principalmente nos fins de semana, quando as entidades estavam fechadas e os venezuelanos ficavam à própria sorte pelas ruas e a população residente era incitada a fazer “justiça com as próprias mãos” por lideranças locais (e com a omissão da polícia estadual). O que nos chamou atenção foi que, no mesmo ano de 2018, mesmo com as forças armadas presentes, houve o episódio de expulsão dos venezuelanos em Pacaraima e o assassinato de forma bárbara de um venezuelano em Boa Vista (noticiados pela grande mídia).

\section{Considerações inconclusas}

A militarização federal através das forças armadas tem sido utilizada em várias experiências nos estados brasileiros com o argumento de manter a segurança e a ordem pública e tem recebido críticas de órgãos de defesa dos direitos humanos, inclusive pelas ações negativas, com episódios constantes de violência e violação de direitos dos moradores de determinados territórios. Sua utilização na área humanitária requer atenção dos organismos democráticos e republicanos já que, além de substituírem o lugar das políticas públicas de modo emergencial, como ocorreu com a assistência social no caso de Roraima, têm reproduzido as formas de dominação de classe que moldaram o Estado brasileiro, sobretudo a partir de 1964, com características autocráticas para conter os conflitos sociais.

Verifica-se na experiência estudada que há uma tentativa (exitosa) de utilização das Forças Armadas, responsável pelo uso da força stricto sensu do Estado, na construção do consenso com diferentes instituições e interesses sobre o tema da migração venezuelana. Uma composição diversa e heterogênea 
Revista Brasileira de História \& Ciências Sociais - RBHCS

Vol. 13 No 26, Janeiro - Junho de 2021

de entidades e membros da sociedade civil vem sendo associada ao projeto de acolhida, interiorização e integração dos imigrantes venezuelanos. Em matéria do Jornal G1, de 22 de maio de 2019, consta que o bilionário Carlos Wizard, além de empresário, também Missionário Mormón da Igreja de Jesus Cristo dos Santos dos Últimos Dias, mudou-se para Roraima em 2019 e tem sido um dos grandes articuladores de empregos em outros estados para interiorização dos venezuelanos.

Tem-se estabelecido com a Operação Acolhida, uma verdadeira economia política da imigração venezuelana. Tanto há ganhos econômicos para a região, quanto para entidades privadas que prestam atendimentos, como para empresas que se disponibilizam a recebê-los. Esta economia política também vem acompanhada de uma economia moral, pois produz sentimentos e normas morais para a questão do refúgio.

Após dois anos de realização da pesquisa, consideramos que a assistência social, como política pública de direito dos migrantes, poderia ter ganhado robustez e serviria como referência para outras situações, estabelecendo padrões de procedimentos, garantindo expertise ao Estado brasileiro e ao pacto federativo para a gestão de "abrigos humanitários" e a proteção aos refugiados. Porém, a opção do Estado brasileiro foi a utilização das forças militares, com grande predomínio de voluntarismo e de instituições da sociedade civil na execução das ações. Além de não perceber a imigração como um processo contínuo, que envolve diversas causas e formatos, e que necessita de ações duradouras e sustentáveis. Novos estudos e aprofundamentos teórico-metodológicos poderão nos dizer as consequências dessas opções políticas a médio e longo prazo.

\section{Referências}

ACNUR. Convenção Relativa ao Estatuto dos Refugiados (1951). Disponível

em:

http://www.acnur.org/t3/fileadmin/Documentos/portugues/BDL/Convencao relativa ao Estatuto dos Refugiados.pdf Acesso em: 26/01/2021.

ACNUR. Declaração de Cartagena (1984). Acesso em: 
Revista Brasileira de História \& Ciências Sociais - RBHCS

Vol. 13 No 26, Janeiro - Junho de 2021

http://www.acnur.org/t3/fileadmin/Documentos/portugues/BD Legal/Instru mentos Internacionais/Declaracao de Cartagena.pdf Acesso em: 26/01/2021.

ACNUR. Protocolo de 1967 Relativo ao Estatuto dos Refugiados. Disponível em: http://www.acnur.org/t3/fileadmin/Documentos/portugues/BDL/Protocolo de 1967 Relativo ao Estatuto dos Refugiados.pdf Acesso em 21/03/2017. Acesso em: 26/01/2021.

ACNUR. United Nations High Commissioner for Refugees. Global Trends Forced Displacement 2019. Geneve, 2020.

BARRETO, Luis Paulo Teles Ferreira. A lei brasileira de refúgio - sua história. In: BARRETO, L. P. T. F. (Org.). Refúgio no Brasil: A proteção brasileira aos refugiados e seu impacto nas Américas. 1.ed. Brasília: ACNUR, Ministério da Justiça, 2010, p.12-46.

BRASIL. Constituição Federal da República, 1988.

BRASIL. Lei de Refúgio. Lei $\mathrm{n}^{0}$ 9.474, de 22 de julho de 1997. Define mecanismos para a implementação do Estatuto dos Refugiados de 1951, e determina outras providências. Disponível em: http://www.planalto.gov.br/ccivil 03/leis/L9474.htm. Acesso em: 26/01/2021.

BRASIL. LOAS. Lei 8.742, de 7 de dezembro de 1993. Dispõe sobre a organização da Assistência Social e dá outras providências. Disponível em: http://www.planalto.gov.br/ccivil 03/leis/L8742compilado.htm. Acesso em: 26/01/2021.

CNAS. Tipificação Nacional dos Serviços Socioassistenciais. Resolução 109, de 11 de novembro de 2009.

CORREA, Mariana Almeida Silveira; NEPOMUCENO, Raísa Barcellos; MATTOS, Weslley H. C.; MIRANDA, Carla. Migração por sobrevivência: soluções brasileiras. REMHU, Rev. Interdiscip. Mobil. Hum., Brasília, v.23, p.221-236, 2015.

DI CESARE, Donatella. Estrangeiros residentes: uma filosofia da migração. Belo Horizonte: Ed. Âyiné, 2020.

DW. Fechamento da fronteira afeta refugiados venezuelanos. 2018. Disponível em: https://www.dw.com/pt-br/fechamento-da-fronteira-afetarefugiados-venezuelanos/a-47643952. Acesso em 26/01/2021.

FASSIN, Didier. La economía moral del asilo. Reflexiones críticas sobre la "crisis de los refugiados" de 2015 en Europa. Revista de Dialectología y Tradiciones Populares, vol. LXX, p. 277-290, 2015.

GOMARASCA, Paolo. Dossiê: "Dilemas éticos das migrações" direito de excluir ou dever de acolher? A migração forçada como questão ética. REMHU, Rev. Interdiscip. Mobil. Hum., Brasília, v. 25, p.11-24, 2017. 
Revista Brasileira de História \& Ciências Sociais - RBHCS

Vol. 13 No 26, Janeiro - Junho de 2021

IMDH. Cadernos de Debates Refúgio, Migrações e Cidadania. v. 9, Brasília: Instituto Migrações e Direitos Humanos, 2014.

JUBILUT, Liliana Lyra; MADUREIRA, André de Lima. Os desafios de proteção aos refugiados e migrantes forçados no marco de Cartagena + 30. REMHU Rev. Interdiscip. Mobil. Hum., Brasília, v.22, p. 11-33, 2014.

LEÃO, Augusto Veloso. Como os fluxos migratórios aparecem nas discussões políticas e nas campanhas eleitorais? In: BAENINGER, Rosana; SILVA, João Carlos Jarochinski (Org.). Migrações venezuelanas. São Paulo: UNICAMP, p. 355-368, 2018.

MINISTÉRIO DA JUSTIÇA E SEGURANÇA PÚBLICA. CONARE concede refúgio para 21.00o venezuelanos. 2019. Disponível em: https://www.novo.justica.gov.br/news/conare-concede-refugio-para-21-milvenezuelanos Acesso em 26/01/2021.

MOREIRA, Juliana Bertino. Redemocratização e direitos humanos: a política para refugiados no Brasil. Revista Brasileira de Política Internacional. Vol. 53, p.111-129, 2010.

ONU. International Migration Report 2015. Disponível em: http://www.un.org/en/development/desa/population/migration/publications/ migrationreport/docs/MigrationReport2015 Highlights.pdf. Acesso em 26/01/2021.

PODER JUDICIÁRIO DO ESTADO DE RORAIMA. Decreto 25.681-E de 01/08/2018.

Disponível

em:

http://www.tjrr.jus.br/legislacao/index.php/decretos-estaduais/135-decretosestaduais-2018/1686-decreto-25681-e-de-1-de-agosto-de-2018. Acesso em 26/01/2021. 